\title{
Mapping the Quality of Informed Consent for Major Surgical Procedures in Public Dental Hospitals in Khartoum State, Sudan, 2017: A Cross Sectional Study
}

\author{
Rawan A Akasha ${ }^{1}$, Lamis Beshir ${ }^{2}$ and Maisa El-Fadul ${ }^{1 *}$ \\ ${ }^{1}$ University of Medical Sciences and Technology, Khartoum, Sudan \\ ${ }^{2}$ Sudan Medical Specialization Board, Khartoum, Sudan
}

"Corresponding author: Maisa El-Fadul, University of Medical Sciences and Technology, Khartoum, Sudan, Tel: +249924622759; E-mail: maisa.elfadul@yahoo.com

Received date: October 31, 2018; Accepted date: December 6, 2018; Published date: December 10, 2018

Copyright: ( 2018 Akasha RA, et al. This is an open-access article distributed under the terms of the Creative Commons Attribution License, which permits unrestricted use, distribution, and reproduction in any medium, provided the original author and source are credited.

\begin{abstract}
Background: Informed Consent (IC) is a valuable document that remains central to medical ethics because it supports patient autonomy. Even after signing an IC document, many patients in developing countries are still illinformed. Little is known about the quality of the IC document and the process related to surgical dental procedures in Sudan.
\end{abstract}

Objectives: This study was conducted to determine the availability of consent form and to assess the quality of IC form and its processing in Khartoum governmental dental hospitals by comparing them to international standards and between each other with regard to comprehensiveness and simplicity of the form.

Methodology: A cross-sectional study was carried out in three public dental hospitals- 1) United Police Force Hospital (UPFH), 2) Khartoum Dental Teaching Hospital (KDTH) and 3) Military Hospital-Omdurman (MH-O) in which 12 consent forms were reviewed during the period from January to March 2017 and a total of 50 patients were recruited. The study sample was taken from patients who underwent major oral and maxillofacial surgical procedures in these hospitals. International standards on availability and quality of IC document were used to elaborate checklists to collect appropriate data. Patients were also interviewed to assess their comprehension of IC. Descriptive and inferential statistics have been done to analyze the quality of IC and patients comprehension.

Results: A generic type of IC was available in all governmental dental hospitals but was not modified according to the type of major surgical procedure. The available IC elements in the $\mathrm{MH}-\mathrm{O}$ found in comparison to international standards was $(61.5 \%),(53.8 \%)$ in $\mathrm{KDTH}$ and $(46.2 \%)$ in UPFH. In regards to the comprehensiveness of each IC element and the use of local understandable language, it was found to be average in MH-O and KDTH and low in UPFH. Patient's comprehension of IC was poor with a total of $54 \%$ of all patients that did not understand the IC at all, $42.3 \%$ of those being illiterate. Age and level of education was significantly associated with an understanding of IC elements.

Conclusion: The Governmental dental hospitals in Sudan do not have tailored IC. The IC was neither comprehensive nor understandable to the patients.

Keywords: Informed consent; Medical ethics; Surgical dental procedures; Khartoum; Sudan

Abbreviations: IC: Informed Consent; UMST: University of Medical Sciences and Technology; KDTH: Khartoum Dental Teaching Hospital; MH-O: Military Hospital-Omdurman; UPFH: United Police Force Hospital

\section{Introduction}

The physician-patient relationship remains one of the cornerstones of medical care where trust and communication result in better health outcomes. IC is a process of information transfer between a patient and a doctor that leads to patient's approval to go through a certain clinical procedure [1]. So patients can be fully informed before deciding to undergo a major treatment, sufficient data should be disclosed to patients for both ethical and lawful purposes [2,3]; IC must be documented in writing. Under dire circumstances, courts may find performing a procedure on a patient without his or her consent as a form of battery [4].

Any patient's preparation for medical intervention involves more than getting the patient to sign a written consent form. Nevertheless, a full IC's formality and finality separate it from the everyday regular patient education. In most countries, surgery, anesthesia, and other invasive or complex medical or radiologic procedures require a signature on a document form. Standards on when and how formal IC must be given differ from one place to another but international guidelines do exist. The main ethical argument and reasons behind IC focus on autonomy [4,5], trust [6], self-ownership [7], non-domination and personal integrity [8]. Legal arguments include protection, preventing abusive conduct [9] and any nonessential procedures. Both arguments essentially complement each other as demonstrated in Figure $1[10]$. 


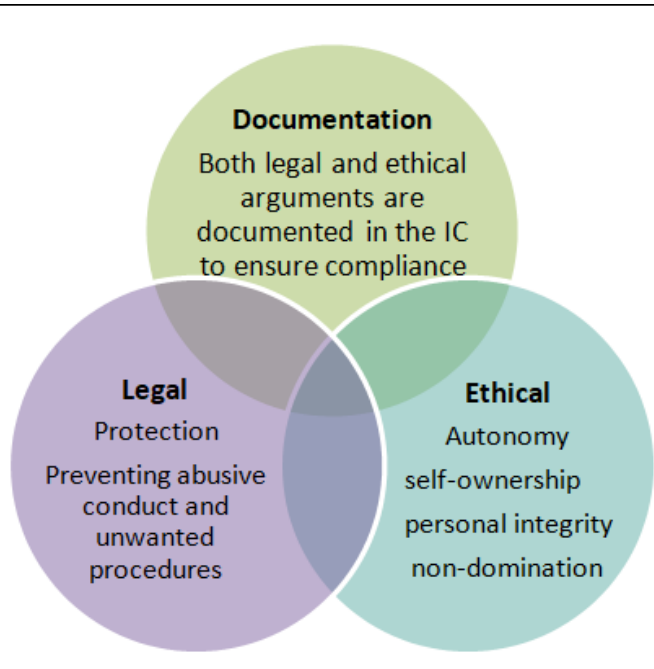

Figure 1: Arguments behind Informed Consent (IC).

Both ethical and legal arguments complement each. The documentation of IC ensures that these values are met and complied with [10].

International regulations illustrate the minimum requirements for a properly executed IC form and state that this form must be in the chart of a patient before surgery or any other medical intervention. These regulations also specify that the information must be given in a language or means of communication that the patient understands.

An exhaustive and thorough IC process must at least contain those mentioned elements:

- The patient's role in the decision-making process must be talked over and reviewed with the patient

- The clinical diagnosis and recommended treatment must be explained well and discussed

- Other possible choices to the recommended treatment (including the option of no treatment) must be talked over and reviewed with the patient

- Risks and benefits of the recommended treatment must be explained and compared to the risks and benefits of other possible treatments

- Associated uncertainties or concern should be discussed

- Patient's comprehension and awareness of the information provided must be evaluated; and

- Patient's choice (and thereby consent) must be obtained [11]

\section{The aim of the study}

- To explore the current practice of IC in a resource-limited setting. We hypothesize that the current practices in public dental hospitals maybe inadequate and often hampered by growing rates of health illiteracy around Sudan

- To assess the availability and documentation of IC in public dental hospitals in Khartoum

- To determine the quality of IC form in public dental hospitals

- To assess patients' comprehension of IC elements

- We believe that understanding the current situation and gaps in the practice of IC in public dental hospitals will help in the prospective improvement of the process to ensure a patientcentered and a context-specific IC

- We think of IC as a continuum where information should always be provided when sought to ensure patients are truly informed rather than a procedural document that needs to be signed. The type of information to be disclosed should remain simple, understandable and context-specific. We, therefore, encourage the use of a consistent, up to international standards IC template as a starting point for the creation of forms for various procedures to improve the consistency and quality in the forms

\section{Literature review}

Research and data regarding the quality and availability of IC remain limited in Africa. Sudan is not an exception. Few studies were conducted to evaluate the quality of IC obtained by doctors and nurses from patients attending public hospitals and to assess whether complete information was disclosed to patients to enable them to provide a well IC. Chima [12], Taiwo and Kassin [13] revealed that the quality of IC was generally poor, understanding of key elements such as benefits, confidentiality, and voluntariness was low. Responses from doctors, nurses and patients revealed that physicians often are unaware of legal and ethical topics related to constructing IC forms, and execution in practice was inadequate, with a deficiency in knowledge of basic consent elements, local laws, and regulations. Potentially compromising factors of understanding were poverty, illiteracy, therapeutic misconception and confusion [13].

Assessing the quality of IC forms remains crucial to ensure that key messages have been truly received, to improve the quality of care and better professionalism from dental surgeons and staff. So far and to the best of our knowledge, a research on verbal or written IC has not yet been conducted in the dental setting in Sudan; the current study, therefore, aims to fill the gap.

\section{Material and Methods}

\section{Study design}

A cross-sectional study was carried out in Khartoum state with an aim to determine the IC availability and adequacy in addition to patients' comprehension of IC document.

All three governmental dental hospitals were covered; they were namely $\mathrm{KTH}, \mathrm{MH}-\mathrm{O}$, and UPFH. The study focused on major dental surgical procedures are defined by the hospital policy and local dental protocols and classified as surgical procedures done in the oral and maxillofacial area. Such procedures are surgically invasive and require more excessive intervention in the hard and soft tissue of the region. They include: dentoalveolar surgery and maxillofacial implants, cosmetic surgery of the head and neck, corrective jaw surgery (orthognathic surgery), reconstructive surgery (both tissue transfer and trauma), head and neck cancer and benign and malignant lesions of salivary gland, surgery for cleft lip and palate, and other congenital facial deformities and other unspecified surgery. All patients who underwent major dental surgeries in the three target hospitals, from January to March 2016, were included in the study. This led to a sample of 50 patients. IC was sought from all study participants. Accordingly, 50 IC documents were reviewed based on international standards and the Interpretive Guidelines for IC set by the Centers for Medicare and Medicaid Services in Baltimore [14]. 
A structured interview has been conducted to assess patient comprehension of IC elements. Comprehension and simplicity were evaluated using operational definition according to clarity. Comprehension was evaluated by the understanding of the patient to the form; first, whether or not the patient was able to internalize the form information written in the form, i.e. each IC elements and second, how much did the patient internalize from the consent form overall. Simplicity was evaluated by the use of simple understandable language in the form (using layman terms only) and free from medical jargon. The overall comprehension was assessed by asking the patient to rate the whole IC document according to how much information they were able to understand. The simplicity of the form was also examined by two independent reviewers to check whether the document was written in local understandable language. Results were written as 1 for very low (patient had no understanding and no content simplicity), 2 for low (patient barely understood content and poor content simplicity), 3 for moderate (patient understood half of the content and half of the content was simple), 4 for high (patient understood more than half of the content and more than half of the content was simple) and 5 for very high (patient understood all of the content and all the content was simple).

For comparative analysis background data about the hospital, type of dental surgeries has been collected in addition to the sociodemographic characteristics of the study participants.

Data was entered and processed using the Statistical Package for Social Sciences (SPSS) version 17. Variables included IC forms elements, type of major oral and maxillofacial surgery, dental hospital, patient's education level, and patient's age and gender. Descriptive statistics were conducted to generate frequency tables. Inferential analysis has been conducted using Chi-square test. $\mathrm{P}$ value $<0.05$ was considered statistically significant.

\section{Sampling technique and sample size}

A convenience sampling technique was used to include the target population of 50 patients available during the period of the study (January to March 2016) in the three target hospitals.

\section{Survey instruments}

The survey used modified checklists was to check availability and adequacy of IC document according to international guidelines. An interview-based questionnaire was carried out to assess patient comprehension of IC document.

\section{Ethical Approval and Consent to Participate}

Ethical approval was sought from UMST committee and Khartoum Institution review board. Permission from KDTH, $\mathrm{MH}-\mathrm{O}$ and the UPFH was obtained. Written IC was sought from all literate study participants and verbal consent from illiterate ones as indicated in National Research Ethics committee guidelines (waiver section). Privacy and confidentiality was ensured by coding the name of the governmental dental hospitals to make the data anonymous.

\section{Results}

Twelve ICs were reviewed in this study for quality assessment. Fifty patients were interviewed to assess their understanding and comprehension. All the participants responded to all the questions, leading to a response rate of $100 \%$.

The most surgical procedure performed in UPFH was reconstructive surgery $(40 \%, n=4)$, head and neck cancer $(30 \%, n=9)$ in $\mathrm{KDTH}$; and unspecified surgery $(30 \%, \mathrm{n}=3)$ and reconstructive surgery $(30 \%, n=3)$ in $\mathrm{MH}-0$ (Table 1$)$.

\begin{tabular}{|c|c|c|c|}
\hline \multirow[b]{2}{*}{ Type of surgical procedure } & \multicolumn{3}{|c|}{ Governmental dental hospital } \\
\hline & $\begin{array}{l}\text { United Police } \\
\text { Force Hospital }\end{array}$ & $\begin{array}{l}\text { Khartoum } \\
\text { Dental } \\
\text { Teaching } \\
\text { Hospital }\end{array}$ & $\begin{array}{l}\text { Military Hospital- } \\
\text { Omdurman }\end{array}$ \\
\hline Dentoalveolar surgery and maxillofacial implants & $0(0 \%)$ & $2(4 \%)$ & $1(2 \%)$ \\
\hline Cosmetic surgery of the head and neck & $0(0 \%)$ & $0(0 \%)$ & $0(0 \%)$ \\
\hline Corrective jaw surgery (orthognathic surgery) & $1(2 \%)$ & $2(4 \%)$ & $0(0 \%)$ \\
\hline Reconstructive surgery (both tissue transfer and trauma) & $4(8 \%)$ & $6(12 \%)$ & $3(6 \%)$ \\
\hline Head and neck cancer and benign and malignant lesions of salivary gland & $2(4 \%)$ & $9(18 \%)$ & $2(4 \%)$ \\
\hline Surgery for cleft lip and palate, and other congenital facial deformities & $2(4 \%)$ & $4(8 \%)$ & $1(2 \%)$ \\
\hline Unspecified surgery & $1(2 \%)$ & $7(14 \%)$ & $3(6 \%)$ \\
\hline Total & $10(20 \%)$ & $30(60 \%)$ & $10(20 \%)$ \\
\hline
\end{tabular}

Table 1: Distribution of major oral and maxillofacial surgical procedure by hospitals (\% out of overall surgical procedures).

Regarding the percentage of availability of IC elements, $\mathrm{MH}-\mathrm{O}$ ranked first $(61.5 \%, 8 / 13$ elements required by international regulations), followed by $\mathrm{KDTH}(53.8 \%, 7 / 13)$ and UPFH $(46.2 \%$, 6/13) (Table 2). Further analysis of comprehensiveness of IC document, revealed that documents were written in the acceptable language in the three hospitals yet gap in patent rights and alternative procedures were noticed across the hospitals (Table 3). The overall understanding was found to be average in $\mathrm{MH}-\mathrm{O}$ and $\mathrm{KDTH}$ and low in UPFH (Table 3). 
Citation: Akasha RA, Beshir L, El-fadul M (2018) Mapping the Quality of Informed Consent for Major Surgical Procedures in Public Dental Hospitals in Khartoum State, Sudan, 2017: A Cross Sectional Study. Dentistry 8: 523. doi:10.4172/2161-1122.1000523

Page 4 of 7

\begin{tabular}{|c|c|c|c|c|}
\hline \multirow{2}{*}{ S. No. } & \multirow{2}{*}{ Checklist element } & \multicolumn{3}{|c|}{ Availability } \\
\hline & & $\begin{array}{l}\text { United Police Force } \\
\text { Hospital }\end{array}$ & $\begin{array}{l}\text { Khartoum Dental Teaching } \\
\text { Hospital }\end{array}$ & Military Hospital-Omdurman \\
\hline 1. & Title/heading & Yes & Yes & Yes \\
\hline 2. & Name and signature of the patient & Yes & Yes & Yes \\
\hline 3. & Legal representative & Yes & Yes & Yes \\
\hline 4. & Name of procedure(s) and its background & No & Yes & Yes \\
\hline 5. & Name of all practitioners performing the procedure & No & No & No \\
\hline 6. & Risks and foreseeable complication & Yes & Yes & Yes \\
\hline 7. & Benefits & No & No & No \\
\hline 8. & Alternative procedures and treatments & No & No & No \\
\hline 9. & Risks of alternatives procedures and treatments & No & No & No \\
\hline 10. & Right for refusal & No & No & No \\
\hline 11. & Date and time consent is obtained & Yes & Yes & Yes \\
\hline 12. & Signature of the person witnessing the consent & No & No & Yes \\
\hline 13. & $\begin{array}{l}\text { Name and signature of the person who explained the } \\
\text { procedure to the patient or guardian }\end{array}$ & Yes & Yes & Yes \\
\hline & Total (\%) & $6(46.2 \%)$ & $7(53.8 \%)$ & $8(61.5 \%)$ \\
\hline
\end{tabular}

Table 2: Distribution of availability of ICs elements across governmental dental hospitals.

\begin{tabular}{|c|c|c|c|}
\hline Measures & UPFH & KDTH & MH-O \\
\hline Simplicity (written in local understandable language) & 3 (average) & 4 (high) & 5 (very high) \\
\hline Comprehensiveness of diagnosis and procedure & 2 (low) & 4 (high) & 3 (moderate) \\
\hline Comprehensiveness of benefits & 2 (low) & 3 (moderate) & 4 (high) \\
\hline Comprehensiveness of rights & 2 (low) & 3 (moderate) & 1 (very low) \\
\hline Comprehensiveness of risk & 4 (high) & 5 (very high) & 2 (low) \\
\hline Comprehensiveness of alternative treatment & 1 (very low) & 1 (very low) & 1 (very low) \\
\hline Overall & 2 (low) & 3 (moderate) & 3 (moderate) \\
\hline
\end{tabular}

Table 3: Assessment of comprehensiveness of IC document according to simplicity and clarity.

Patient comprehension of diagnosis and procedure was found to be the highest (100\%) in all dental hospital followed by the risk of the surgical procedure and right for refusal (80\%-53.3\%). The least comprehended element was found to be the alternative treatment and procedures (43.3\%-20\%) (Figures 2-4).

Concerning the level of understanding of all patients, 54\% (27/50) did not understand the 13 elements of the IC at all, $24 \%(12 / 50)$ partially understood and 22\% (11/50) fully understood (Table 4). Cross-tabulation was done to assess whether there is a relation between the level of understanding of IC elements and demographic characteristics (Gender, Age and Education level). 67\% among illiterate patients didn't understand them at all. 51.9\% of both genders didn't understand the elements on the form and $32 \%$ of those patients were above 60 years of age. There was no significant relationship between the gender and the level of understanding ( $p$ value $=0.664$ ) but there was a significant relation between age and level of understanding ( $p$ value $=0.006)$ as well as education level and level of understanding $(\mathrm{p}$ value $=0.007$ ) (Table 5). 
Citation: Akasha RA, Beshir L, El-fadul M (2018) Mapping the Quality of Informed Consent for Major Surgical Procedures in Public Dental Hospitals in Khartoum State, Sudan, 2017: A Cross Sectional Study. Dentistry 8: 523. doi:10.4172/2161-1122.1000523

Page 5 of 7

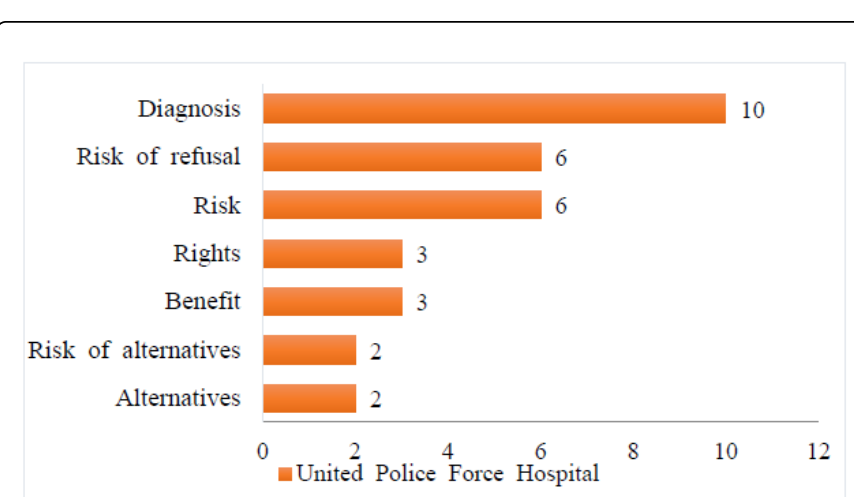

Figure 2: Perception of patient on Informed Consent (IC) comprehension by an element in United Police Force Hospital $(\mathrm{UPFH})(\mathrm{n}=70)$.

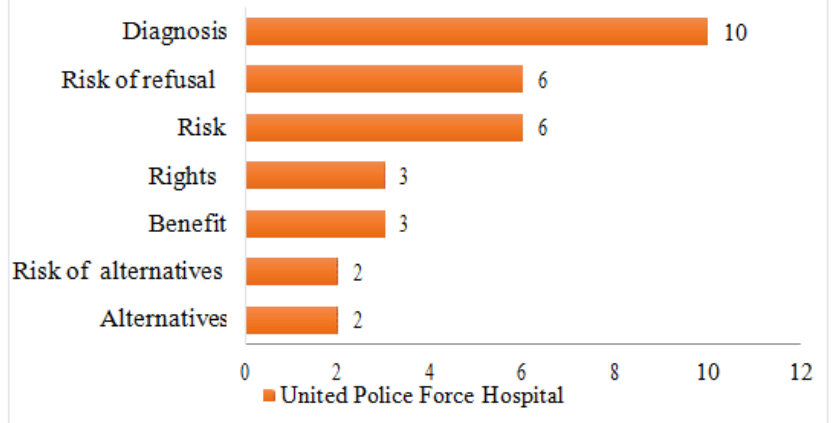

Figure 3: Perception of patient on Informed Consent (IC) comprehension by an element in Khartoum Dental Teaching Hospital (KDTH) $(\mathrm{n}=210)$.

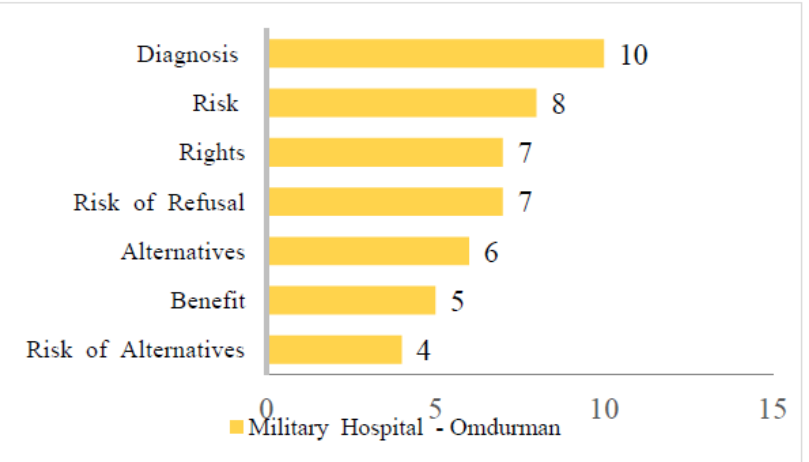

Figure 4: Perception of patient on Informed Consent (IC) comprehension by an element in Military Hospital-Omdurman $(\mathrm{MH}-\mathrm{O})(\mathrm{n}=70)$.

A total number of 12 checklists were used in this study for informed consent assessment $(\mathrm{n}=12)$ and a total number of 50 checklists were used to question 50 patients on their comprehension. The response rate was $100 \%$ of all participants of patients who agreed to be questioned.

\begin{tabular}{|l|l|l|l|}
\hline $\begin{array}{l}\text { Understanding } \\
\text { level }\end{array}$ & $\begin{array}{l}\text { United Police } \\
\text { Force } \\
\text { Hospital } \\
\text { (UPFH) } \\
(\mathbf{n}=10)\end{array}$ & $\begin{array}{l}\text { Khartoum } \\
\text { Dental Teaching } \\
\text { Hospital (KDTH) } \\
(\mathbf{n = 3 0 )}\end{array}$ & $\begin{array}{l}\text { Military Hospital- } \\
\text { Omdurman (MH-O) } \\
(\mathbf{n}=10)\end{array}$ \\
\hline Did not understand & 6 & 17 & 4 \\
\hline Partially understand & 2 & 7 & 3 \\
\hline Fully understand & 2 & 6 & 3 \\
\hline
\end{tabular}

Table 4: Distribution of level of understanding Informed Consent (IC) elements by type of dental hospital.

\begin{tabular}{|c|c|c|c|c|c|}
\hline Variable & $\begin{array}{l}\text { Did not } \\
\text { understa } \\
\text { nd }\end{array}$ & $\begin{array}{l}\text { Partially } \\
\text { understa } \\
\text { nd }\end{array}$ & $\begin{array}{l}\text { Fully } \\
\text { understa } \\
\text { nd }\end{array}$ & Total & $\begin{array}{l}P . \\
\text { value }\end{array}$ \\
\hline \multicolumn{6}{|l|}{ Age category } \\
\hline$>20 \mathrm{yrs}$ & $0(0 \%)$ & $1(1.9 \%)$ & $0(0 \%)$ & $1(1.9 \%)$ & \\
\hline $20-40$ yrs & $0(0 \%)$ & $1(1.9 \%)$ & $4(7.7 \%)$ & $5(9.6 \%)$ & $0.006^{\star *}$ \\
\hline $41-60$ yrs & $\begin{array}{l}11 \\
(21.2 \%)\end{array}$ & $8(15.4 \%)$ & $5(9.6 \%)$ & $\begin{array}{l}24 \\
(46.2 \%)\end{array}$ & \\
\hline $60+y r s$ & $\begin{array}{l}16 \\
(30.8 \%)\end{array}$ & $4(7.7 \%)$ & $2(3.8 \%)$ & $\begin{array}{l}22 \\
(42.3 \%)\end{array}$ & \\
\hline \multicolumn{6}{|l|}{ Gender } \\
\hline Male & $9(17.3 \%)$ & $3(5.8 \%)$ & $4(7.7 \%)$ & $\begin{array}{l}16 \\
(30.8 \%)\end{array}$ & \\
\hline Female & $\begin{array}{l}18 \\
(34.6 \%)\end{array}$ & $\begin{array}{l}11 \\
(21.2 \%)\end{array}$ & $7(13.5 \%)$ & $36(69.2)$ & 0.664 \\
\hline \multicolumn{6}{|l|}{ Education level } \\
\hline Illiterate & $\begin{array}{l}22 \\
(42.3 \%)\end{array}$ & $7(13.5 \%)$ & $2(3.8 \%)$ & $\begin{array}{l}31 \\
(59.6 \%)\end{array}$ & $0.007^{* *}$ \\
\hline Primary school & $1(1.9 \%)$ & $2(3.8 \%)$ & $0(0 \%)$ & $3(5.8 \%)$ & \\
\hline $\begin{array}{l}\text { High } \\
\text { graduate }\end{array}$ & $4(7.7 \%)$ & $4(7.7 \%)$ & $6(11.5 \%)$ & $\begin{array}{l}14 \\
(26.9 \%)\end{array}$ & \\
\hline $\begin{array}{l}\text { University and } \\
\text { above }\end{array}$ & $0(0 \%)$ & $1(1.9 \%)$ & $3(5.7 \%)$ & $4(7.7 \%)$ & \\
\hline
\end{tabular}

Table 5: Association between socio-demographic characteristics and understanding of informed consent elements using Chi and Fisher exact test.

Results showed a number of each type of dental procedure performed in 3 governmental dental hospitals. The most surgical procedure performed in UPFH were reconstructive surgery, head and neck cancer in KDTH and both unspecified surgery and reconstructive surgery in $\mathrm{MH}-\mathrm{O}$.

\section{Discussion}

IC remains the foremost central act of respecting the autonomy and dignity of patients. The generic practice of IC observed in this study in the dental surgery setting suggests that IC is still thought of as a propositional hypothetical document or process that is rather incomplete and non-specific. 
The main objective of our study was to assess the availability and quality of IC related to major oral and maxillofacial surgical procedures in governmental hospitals in Khartoum, Sudan.

Regarding the availability of IC, all the three governmental dental hospitals had ICs documents. However, regarding the quality of IC, all of the IC lacked elements that were vital for the consent process. ICs of different surgical procedures were found to be the same in each hospital and were not tailored according to the surgical procedure. This might be explained due to limited institutional capacity in "know how" related to consent document design and development.

Concerning the assessment of IC quality form in governmental dental hospitals compared to international standards, the quality of IC was found to be generally unsatisfactory with regard to IC elements listed in international regulations. These regulations spell out the minimum requirements for a properly executed IC form. This is similar to the results of the study conducted in Saudi Arabia where the quality of IC was found to be poor [15]. Related results are also shown in the study conducted in Sudan in the pediatric surgical setting by AlaEldin Ahmed Hassan Abdalla which concluded that the IC process is of poor quality and far beyond international standards and that the staffs were unaware of the key elements of the IC [16].

Observation revealed that forms weren't written in local understandable language or layman terms and contained a lot of medical jargon unlike the Queensland Health's ideal and customized IC forms [17].

This may explain why most IC documents are not used to guide the consent process but merely used for archival purposes and to avoid the medico-legal hurdle. Instead, the consent process is more reliant on the verbal aspect which is done in local understandable language but comes with disadvantages pertaining to which extent the verbal consent is guided and addresses all the IC elements.

Regarding patient's comprehension, $22 \%$ of all patients fully understood the IC which shows a low percentage of understanding similar to the study conducted in Nigeria where patients also had a poor level of understanding to key IC elements such benefits and rights [13].

Results of the inferential analysis showed a significant relationship between the level of patients' understanding of IC to the patient's age and level of education. This settles with the results of a study conducted by Kenneth Amaechi Agu and Emmanuel Ikechukwu Obi about the attitude towards IC practice in a developing country which showed that knowledge of IC practice increased with level of education but most of the participants irrespective of educational status would want to be involved in decisions about their healthcare [18]. Both studies ensure the need to work on IC quality and the need for enhancing the relationship and gaining trust between health care providers and patients. This will help ensure patient's autonomy, protection, self-ownership, and personal integrity and prevents from coercive and abusive conduct.

One of the reasons behind low patient's comprehension is the lack of knowledge of the medical provider towards the IC process and need to emphasize the procedure steps, benefits, risk, alternative treatment and their risks as well as rights for refusal as in the study conducted in South Africa which showed that the doctors and nurses providing the consents are unaware of legal and ethical requirements related to constructing IC forms. Similar results were also found in Sudan on a research involving the evaluation of the implementation of IC in obstetrics and gynecology operations where doctors had poor knowledge of information that is within the IC [19]. Our findings are also consistent with another study that conducted in Sudan to explore the attitudes of doctors in obtaining IC to surgical operations in public hospital in Khartoum done by Dyaeldin M Elsayed and Abdelhali Nur Hassan [20] they revealed that IC is poorly observed in surgical practice in Sudan. It also stated that some authors find IC as unilateral dialogue due to the imbalance of knowledge and authority between physicians and patients and those clinicians often overlook explanatory elements in ICs, which, alone, cannot prepare individuals to make the right decision for treatment or surgery [20]. Despite the fiduciary nature of physician-patient relationship sets that foundation for communication by both parties. However, physicians may also have the tendency to guide processes of disclosure of information to what they seem to think is adequate. In other cases, skewed information is given out of concern not to worry the patient unduly.

\section{Limitation}

We recognize several limitations of this study. The study has only been conducted in dental public hospitals and therefore might not be representative of the overall dental practice in Khartoum. Therefore, it lacks generalizability. This factor may also bias the results of the study as the patients who attend public hospitals are more likely to be more educationally disadvantaged. This has been highlighted in sociodemographic characteristics of patients in Table 5. A wide-scale study that includes patients in private dental hospitals will ensure a more representative study population.

Further in-depth interviews were needed to improve the understanding of risk factors of poor recalling and comprehension of IC.

\section{Conclusion}

All governmental dental hospitals in Sudan do not have tailored IC according to the surgical dental procedure and only have an average of 7 out of 13 international standard elements. Their practice was quite varied with regard to process and staff performing the IC process. There is a significant relationship between the level of understanding of the patient to the IC and the patient's age and level of education. No significant relationship was found between level of patient's understanding and the gender of the patient.

Further evaluation studies in IC in the dental practice are needed to reach consensus on the current gaps in the field so the process and the quality of IC can be optimized for dental surgery.

\section{Competing Interests}

The author declares that they have no competing interests.

\section{Consent for Publication}

This data is the intellectual property of the University of Medical Sciences and Technology (UMST). The right for publication has been granted to UMST as data owner.

\section{Funding}

This research was exclusively funded by both the principal investigator and UMST. 
Citation: Akasha RA, Beshir L, El-fadul M (2018) Mapping the Quality of Informed Consent for Major Surgical Procedures in Public Dental Hospitals in Khartoum State, Sudan, 2017: A Cross Sectional Study. Dentistry 8: 523. doi:10.4172/2161-1122.1000523

Page 7 of 7

\section{Authors' Contributions}

RAA is the chief author, designed the study, collected the data, performed the analysis and contributed to research conceptualization and wrote the initial draft of the manuscript. I supervised the study during all the steps and helped in drafting this paper and finalizing the manuscript. LB contributed to drafting the manuscript and critically reviewed it for important intellectual content. All authors reviewed and approved the final version of the manuscript.

\section{Availability of Data and Material}

The data that support the findings of this study are available from University of Medical Science and Technology but restrictions apply to the availability of these data, which are used under the license for the current study, and so are not publicly available. Data are however available from the authors upon reasonable request and with permission of UMST.

\section{Acknowledgment}

The authors would like to acknowledge Dr. Muram Hatim, Dr. Weam Jamal, and Dr. Basil Abdelwahab for their support during data collection.

\section{References}

1. American Medical Association (1998, updated March 2005) Informed Consent.

2. Edwards SJ, Lilford RJ, Thornton J, Hewison J (1998) Informed consent for clinical trials: in search of the "best" method. SocSci Med 47: 1825-1840.

3. Wescott, Lebanon PA (2005) Medical-legal issues in risk management: improving quality of care and reducing medical liability. Wescott Professional Publications.

4. Ruth RF, Beauchamp TL (1988) A history and theory of informed consent. Am Polit Sci Rev 82: 271.

5. National commission for the protection of human subjects of biomedical and behavioral research (1979) "The Belmont Report".
6. Jennifer J (1994) Promise-keeping and the doctor-patient relationship. In Principles of Health Care Ethics, edited by R. Gillon. Chichester: John Wiley and Sons.

7. John L (1988) Second treatise on civil government. In Locke: Two treatises of government, edited by $\mathrm{P}$ Laslett. Cambridge: Cambridge University Press.

8. Ronald D (1983) Comment on Narveson: In defence of equality. Soc Philos Policy 1: 24-40.

9. Neil CM, O'Neill O (2007) Rethinking informed consent in bioethics. Cambridge: Cambridge University Press.

10. Hall DE, Prochazka AV, Fink AS (2012) Informed consent for clinical treatment. CMAJ 184: 533-540.

11. Braddock CH, Fihn SD, Levinson W, Jonsen AR, Pearlman RA (1997) How doctors and patients discuss routine clinical decisions. Informed decision making in the outpatient setting. J Gen Intern Med 12: 339-345.

12. Chima SC (2013) Evaluating the quality of informed consent and contemporary clinical practices by medical doctors in South Africa: An empirical study. BMC Medical Ethics 14: S3.

13. Taiwo OO, Kass N (2009) Post-consent assessment of dental subjects' understanding of informed consent in oral health research in Nigeria. BMC Medical Ethics 10.

14. Federal Code (Title 42 C.F.R. $\$ 482.51$ (b) (2)) Interpretive Guideline A-0392

15. Quality of informed consent for invasive procedures in central Saudi Arabia. International Journal of General Medicine 5: 269-275.

16. Alaeldin Ahmed H Abdallla. Assessment and Evaluation of the Pediatric Surgical Informed Consent process related to common surgical procedurers in public, private and main referral hospitals in Khartoum Sudan.

17. Health.qld.gov.au. (2017). Informed Consent-Maxillofacial|Queensland Health. Available at: https://www.health.qld.gov.au/consent/html/ sub_specialties/maxillofacial

18. Agu K, Obi E, Eze B, Okenwa W (2014) Attitude towards informed consent practice in a developing country: a community-based assessment of the role of educational status. BMC Medical Ethics 15.

19. Umbeli T, Mariam AA, Elhadi MA (2009) Evaluation of Implementation of Informed consent in obstetrics and gynecology operations in Khartoum Sudan 2009. Pub Journal of Medical Sciences 5: 173-177.

20. Elsayed DM, Nur Hassan A (2006) Informed consent practice in sudan. Bioethics Exchange 1. 